\title{
Lanthanum Carbonate - A New Attractive Therapy in Management of Uncontrolled Hyperoxaluria
}

\author{
Agnieszka Pozdzik ${ }^{1,2}$, Anja Verhulst ${ }^{3}$, Joëlle Nortier ${ }^{1,2}$, Thierry Roumeguère ${ }^{2,4}$, Patrick C D'Haese ${ }^{3}$ and A Michel Daudon ${ }^{5,6}$ \\ ${ }^{1}$ Department of Nephrology, Dialysis and Renal Transplantation, CUB Erasme Hospital, Université Libre de Bruxelles, Brussels, Belgium \\ ${ }^{2}$ Diagnosis, Treatment and Prevention of Urinary Stones Center, CUB Erasme Hospital, Université Libre de Bruxelles, Brussels, Belgium \\ ${ }^{3}$ Department of Biomedical Sciences, Laboratory of Pathophysiology, University of Antwerp, Wilrijk, Belgium \\ ${ }^{4}$ Department of Urology, CUB Erasme Hospital, Université Libre de Bruxelles, Brussels, Belgium \\ ${ }^{5}$ Functional Explorations Service, Tenon Hospital, Paris, France \\ 'INSERM UMRS 1155, UPMC, Paris, France
}

Keywords: Hyperoxaluria; Lanthanum carbonate; Kidney stones

\section{Letter}

In 1842, Golding Bird was the first to describe hyperoxaluria as "a condition, which leads to the formation of a particular kidney stone". Nowadays, hyperoxaluria is a well-known major lithogenic risk factor for nephrocalcinosis and nephrolithiasis and within these clinical settings is considered as important as hypercalciuria [1]. Primary hyperoxaluria is a rare inherited disease caused by mutations in genes involved in the oxalate metabolism which leads to excessive endogenous oxalate synthesis resulting in increased plasma oxalate levels and hyperoxaluria. Worldwide epidemiological data indicate a progressive increase in secondary hyperoxaluria, which is an oxalate homeostasis disorder mainly related to pathologically increased intestinal oxalate absorption or excessive dietary oxalate load [2].

Obviously, hyperoxaluria not only needs to be considered as a major determinant of recurrent calcium oxalate nephrolithiasis but also as a toxic factor responsible for acute and/or chronic tubulointerstitial kidney injury (crystal nephropathy). Hyperoxaluria even under normal urinary calcium excretion generates a supersaturation of calcium oxalate forming whewellite (calcium oxalate monohydrate) crystals in the urine. These crystals are insoluble in water and therefore easily aggregate in the tubular lumen. Retention of these crystals in the intratubular lumen induces tubular epithelial cell injury and interstitial inflammation through NLPRP3-mediated IL- $1 \beta$ secretion [3], which in-turn favors adhesion of whewellite crystals to the tubular epithelium resulting in intratubular or interstitial nephrocalcinosis. This vicious circle, especially in a state of uncontrolled hyperoxaluria, incites chronic NALP3-mediated inflammation and progressive renal dysfunction.

The primary goal of hyperoxaluria management consists in the prevention of whewellite crystal formation/precipitation and ensuing kidney stone formation. Unfortunately, all current therapeutic strategies often fail in their effectiveness and compliance which makes that calcium oxalate stone recurrence is still common and indicates the urgent need for new efficient therapeutic interventions.

Lanthanum carbonate (LC) emerged as an attractive drug for the management of uncontrolled hyperoxaluria at the 19th " Necker's hospital clinico-biological confrontations on urinary stones » in Paris last year (Figure 1). Lanthanum carbonate is a calcium-free, non-resinbased phosphate binder, which is prescribed for the management of hyperphosphatemia in patients with end-stage renal disease since 2004 [4]. Importantly, the bioavailability of an oral dose of LC is extremely low $(\sim 0.001 \%)$ and is not influenced by $\mathrm{pH}$, intestinal inflammation or microflora modifications during enteropathies. Lanthanum undergoes transcellular transport in the liver and is excreted by the hepatobiliary system mainly in the feces (80\%). Renal clearance accounts for only $1.7 \%$ of the total plasma clearance of lanthanum. LC is neither a substrate nor an inhibitor of cytochrome P450 enzymes. There is no evidence that LC interferes with the absorption of vitamin $\mathrm{D}$ or any other fat-soluble vitamin. Clinical studies evaluating the efficacy, tolerability and long-term safety of LC monotherapy have consistently reported that the compound is well tolerated, with no evidence of adverse safety outcomes in bone, gastrointestinal tract, liver or central nervous system [4].

The rationale for the use of lanthanum carbonate (LC) in patients with hyperoxaluria is based on findings from in vitro and in vivo studies [5]. In vitro, lanthanum binds oxalate anions under the formation of insoluble lanthanum-oxalate complexes across the entire $\mathrm{pH}$ range in the gastrointestinal tract. Recently, in a rat model of hyperoxaluria

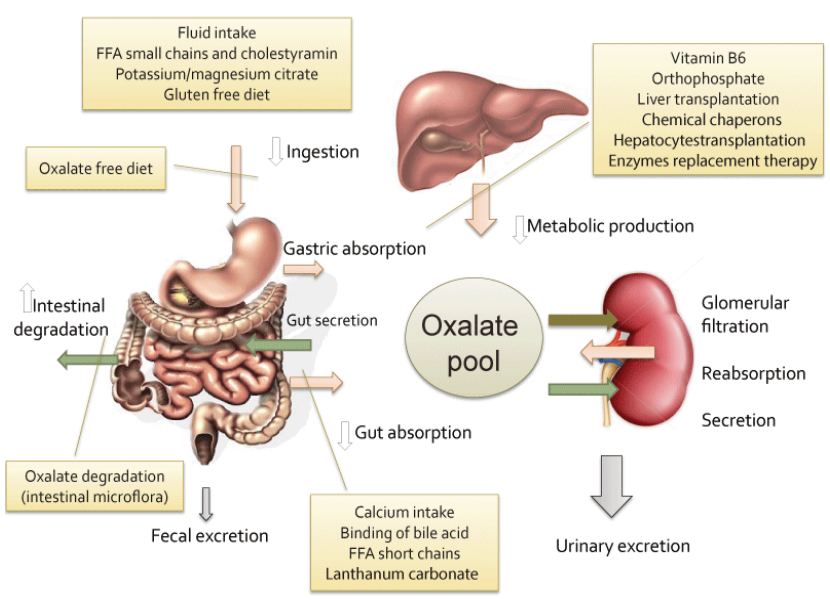

Figure 1: Oxalate homeostasis and various actual and further therapeutic interventions in the management of hyperoxaluria; Oxalate is either present in the diet, or absorbed, secreted and degraded in the intestine or it can be synthetized by the liver from precursors, and filtered, reabsorbed and secreted by the kidney.

*Corresponding author: Agnieszka A Pozdzik, Department of Nephrology, CUB Erasme Hospital, Université Libre de Bruxelles, Route de Lennik 808 B-1070, Brussels, Belgium, Tel: ++ 32-2-555-3334; Fax: +32-2-555-6499; E-mail: Agnieszka.Pozdzik@erasme.ulb.ac.be

Received: September 12, 2015; Accepted: September 17, 2015; Published: September 23, 2015

Citation: PozdzikA, Verhulst A, Nortier J, Roumeguère T, D'Haese PC, et al. (2015) Lanthanum Carbonate - A New Attractive Therapy in Management of Uncontrolled Hyperoxaluria. J Nephrol Ther 5: 215. doi:10.4172/2161-0959.1000215

Copyright: $\odot 2015$ PozdzikA, et al. This is an open-access article distributed under the terms of the Creative Commons Attribution License, which permits unrestricted use, distribution, and reproduction in any medium, provided the original author and source are credited. 
Citation: Pozdzik A, Verhulst A, Nortier J, Roumeguère T, D’Haese PC, et al. (2015) Lanthanum Carbonate - A New Attractive Therapy in Management of Uncontrolled Hyperoxaluria. J Nephrol Ther 5: 215. doi:10.4172/2161-0959.1000215

(male Sprague-Dawley), oral administration of LC significantly reduced the serum oxalate concentration, oxaluria, the formation of calcium oxalate crystals and nephrocalcinosis $[6,7]$.

In view of the above, LC provides interesting perspectives for the medical management of uncontrolled hyperoxaluria, especially in patients presenting with enteric hyperoxaluria (and also in the case of primary hyperoxaluria where the oxalate-lanthanum ions complexes formation could increase the outgoing flow of oxalate from serum to intestine, thus helping to reduce oxalemia and the amount of oxalate delivered to the kidney). Indeed, being a phosphate binder, LC is an attractive therapy with potential benefit for preventing intratubular calcium phosphate precipitation also. Further clinical studies need to be done to evaluate usefulness of $\mathrm{LC}$ as a therapeutic strategy to control hyperoxaluria in human.

\section{Conflict of interests}

Authors have no conflict of interests to disclose

\section{References}

1. Pak CY, Moe OW, Sakhaee K, Peterson RD, Poindexter JR (2005) Physicochemical metabolic characteristics for calcium oxalate stone formation in patients with gouty diathesis. J Urol 173: 1606-1609.

2. Robijn S, Hoppe B, Vervaet BA, D'Haese PC, Verhulst A (2011) Hyperoxaluria: a gut-kidney axis? Kidney Int 80: 1146-1158.

3. Mulay SR, Kulkarni OP, Rupanagudi KV, Migliorini A, Darisipudi MN, et al (2013) Calcium oxalate crystals induce renal inflammation by NLRP3-mediated IL-1beta secretion. J Clin Invest 123: 236-246.

4. Bervoets AR, Behets GJ, Schryvers D, Roels F, Yang Z, et al. (2009) Hepatocellular transport and gastrointestinal absorption of lanthanum in chronic renal failure. Kidney Int 2009; 75: 389-398.

5. Persy VP, Behets GJ, Bervoets AR, De Broe ME, D'Haese PC (2006) Lanthanum: a safe phosphate binder. Sem in Dialysis 19: 195-199.

6. Robijn S, Vervaet BA, Hoppe B, D'Haese PC, Verhulst A (2013) Lanthanum carbonate inhibits intestinal oxalate absorption and prevents nephrocalcinosis after oxalate loading in rats. J Urol 189: 1960-1966.

7. Behets GJ, Dams G, Damment SJ, Martin P, De Broe ME, et al. (2014) Differences in gastrointestinal calcium absorption after the ingestion of calciumfree phosphate binders. Am J Physiol Ren Physiol 306: F61-67. 